\title{
Nanostructured Insecticide Composition through the Incorporation of Natural Abamectin in $\beta$-Cyclodextrin: Activity against Aedes aegypti Larvae
}

\author{
Vanessa C. E. Bittencourt, ${ }^{a}$ Ana M. S. Moreira ${ }^{b}$ Alexandre A. Ferreira, ${ }^{c}$ Erúzia A. E. Ferreira, ${ }^{c}$ \\ Antônio F. F. Gomides, ${ }^{b}$ Cibele V. Rodrigues, ${ }^{b}$ Gustavo F. Martins, ${ }^{d}$ Jeferson G. da Silva, ${ }^{a}$ \\ Keyller B. Borges ${ }^{e}$ and Ângelo M. L. Denadai ${ }^{\oplus * a}$
}

${ }^{a}$ Departamento de Farmácia, Instituto de Ciências da Vida, Universidade Federal de Juiz de Fora (UFJF),
Campus Governador Valadares, 35010-177 Governador Valadares-MG, Brazil

${ }^{b}$ Departamento de Ciências Básicas da Vida, Universidade Federal de Juiz de Fora (UFJF), Campus Governador Valadares, 35010-177 Governador Valadares-MG, Brazil

'Lapidum Assessoria Ltda-ME, 20241-110 Rio de Janeiro-RJ, Brazil

${ }^{d}$ Departamento de Biologia Geral, Universidade Federal de Viçosa, 36570-900 Viçosa-MG, Brazil

${ }^{e}$ Departamento de Ciências Naturais, Universidade Federal de São João del-Rei, Campus Dom Bosco, 36301-160 São João del Rei-MG, Brazil

\begin{abstract}
This study searched for a new pre-formulation based on the natural compound from the class of the avermectins, named abamectin (ABA), in order to improve its action against Aedes aegypti larvae by complexation with $\beta$-cyclodextrin $(\beta C D)$. Concerning the low aqueous solubility of $\mathrm{ABA}$, even in the presence of $\beta C D$, it was also invoked the strategy of working with hydrophobic nanoprecipitates (HNPs). For these purposes, molecular and supramolecular characterizations of 1:1 ABA/ $\beta C D$ complex and evaluation of its toxicity against $A$. aegypti larvae were performed. In the physical-chemistry characterizations, changes in the infrared spectra and thermal profiles in relation to precursors confirmed the occurrence of interactions between $A B A$ and $\beta C D$ in solid state. Nuclear magnetic resonance (NMR) data suggest the inclusion of $A B A$ in $\beta C D$ via benzofuran ring. Isothermal titration calorimetry (ITC) experiments allowed to verify the formation of complex with a 1:1 stoichiometry, which was entropy driven. The dynamic light scattering and zeta potential data from inclusion compounds demonstrated changes in the size of the $\mathrm{ABA} / \beta \mathrm{CD} \mathrm{HNP}$ if compared with the ABA HNP. Finally, the results for biological assays demonstrate that the strategy to prepare the inclusion compound led to an increase in the larvicidal activity in relation to free $\mathrm{ABA}$.
\end{abstract}

Keywords: abamectin, $\beta$-cyclodextrin, hydrophobic nanoprecipitates, Aedes aegypti

\section{Introduction}

Avermectins (AVMs) are pentacyclic lactones obtained by fermentation from Streptomyces avermitilis cultures, belonging to one of the most abundant genres of microorganisms in soil. ${ }^{1}$ Natural AVM, called abamectin (ABA) is a mixture of abamectin-B1a $(85 \%)$ and abamectin$\mathrm{B} 1 \mathrm{~b}(15 \%)$, and has been used as broad-spectrum pesticide in agriculture to combat mites and insects. ABA has low mammalian toxicity, but it is extremely destructive to microcrustaceans and fish due to its ability to reach

*e-mail: angelo.denadai@ufjf.edu.br their brains. ${ }^{2}$ They are lipophilic compounds, practically insoluble in aqueous solutions with high adsorption on organic matter. Due to the easy degradation and adsorption by organic matter, soil and sedimentary particles, it is hardly leached by natural waters. ${ }^{3}$

AVMs have demonstrated larvicide and adulticide activities for several arthropod species with sublethal effects, including malformations, limited mobility, reduction in fertility, and sensory and motor disorders. ${ }^{4,5}$ Two commercial formulation of AVMs, one containing ABA (named MK-936) and another named MK-933, were evaluated against $3^{\text {rd }}$ to $4^{\text {th }}$ instar larvae of Aedes aegypti and were active at very low dosages, being the ABA 
formulation the more effective with lethal concentration at $50 \%$ of population $\left(\mathrm{LC}_{50}\right)$ of $10.40 \mathrm{ppb}^{6}$ Other studies aimed both at the adulticidal and larvicidal application of compounds from this class, showed toxic effect against A. aegypti larvae. ${ }^{7-9}$ These data highlighted the potential of avermectins to combat the A. aegypti mosquito, which has occupied a prominent position among the arthropods that cause risks to public health.

This mosquito is one of the main vectors of numerous arboviruses including dengue, urban yellow fever, chikungunya fever, and zika. Considering that nowadays there are no vaccines nor antiviral drugs with effective action against the dengue, zika and chikungunya viruses, the elimination of their vector is yet the main strategy to be considered in public policies in the whole world. ${ }^{10}$ Thus, actions to combat the A. aegypti have been directed towards the elimination of larvae and mosquitoes through integrated control, which involves physical (mechanical), chemical and biological methods. ${ }^{11}$

Chemical control is a vital part of the programs to combat the mosquito and may be focused on its different evolutionary phases. Thus, the development of new chemical control, which acts in different larval stage becomes essential for rationalize the use of insecticides, with the possibility of reducing the dosages and minimize the environmental impact.

Within this perspective, we have recently studied the combination of $\beta$-cyclodextrin $(\beta C D)^{12-14}$ with insecticides from the class of benzoylphenylureas (BPUs) ${ }^{15}$ and from the class of avermectins, ${ }^{16}$ in order to produce hydrophobic nanoprecipitates, which can be used against $A$. aegypti in larval stages, with lower effective dosages. The formulations with avermectins revealed yet lower toxic effects against human cells.

However, until the present moment, we have not found any work concerning the encapsulation of ABA with cyclodextrin, nor their use against $A$. aegypti larvae. Moreover, it has been reported that pure abamectin is a highly toxic material, although several of its formulated products are of low toxicity to mammals. ${ }^{17,18} \mathrm{ABA}$ can cause nausea, vomiting, diarrhea, drowsiness, agitation and weakness in mild poisoning. On the other hand, severe poisoning can cause hypotension, tachycardia, coma and respiratory failure. These data highlight the importance to search new strategies for environmental using of this compound. ${ }^{19}$

Thus, in this work we have studied the inclusion compound formed by abamectin and $\beta \mathrm{CD}$, which has been characterized in solution and in solid state in order to evaluate the molecular and supramolecular features. In solid state characterizations, the compounds were investigated by Fourier transform infrared spectroscopy (FTIR) and thermal analysis. In solution, interactions were investigated using nuclear magnetic resonance (NMR) techniques. The effect of $\beta C D$ on the $\mathrm{ABA}$ solubility was investigated by phase solubility experiment. ${ }^{20}$ The stoichiometry of the complex and thermodynamic parameters of interaction were determined by isothermal titration calorimetry (ITC). The effect of $\beta C D$ on the size and charge of hydrophobic nanoprecipitates were evaluated by dynamic light scattering (DLS) and zeta potential (ZP) measurements. Finally, the larvicidal activity of the formed $\mathrm{ABA} / \beta \mathrm{CD}$ and $\mathrm{ABA}$ hydrophobic nanoprecipitates (HNPs) was evaluated against $1^{\text {st }}$ and $4^{\text {th }}$ instars of larvae of $A$. aegypti larvae.

\section{Experimental}

\section{Materials}

The ABA (analytical standard) assay high-performance liquid chromatography (HPLC) 97.7 area\% $(97.34 \% \mathrm{~m} / \mathrm{m}$, $\mathrm{B} 1 \mathrm{a}+\mathrm{B} 1 \mathrm{~b})$ and $\beta \mathrm{CD}$ were both obtained from SigmaAldrich (St. Louis, MO, USA) and used without any treatment. All other chemical reagents were of analytical grade and used as received. During all experiments, ultrapure Milli-Q ${ }^{\circledR}$ water (Millipore Plus system, Bedford, MA, USA) was used.

\section{Preparation of the inclusion compound}

The ABA/ $\beta C D$ inclusion compound was prepared by co-precipitation method followed by freeze-dry. Briefly, equimolar amounts of the $\mathrm{ABA}$ and $\beta \mathrm{CD}$ were separately solubilized in ethanol $(15 \mathrm{~mL})$ and Milli- $\mathrm{Q}^{\circledR}$ water $(35 \mathrm{~mL})$, respectively. This proportion was chosen after the determination of stoichiometry by ITC experiment. The ethanolic solution of the host molecule was verted into the aqueous $\beta C D$ solution and submitted to stirring during $24 \mathrm{~h}$. Finally, the suspension formed was placed in rotary evaporator to remove the excess of solvent, and then submitted to the freeze-drying to obtain the desired inclusion compound $(\mathrm{ABA} / \beta \mathrm{CD})$.

The mechanical mixture (MM) was produced by simple mixture of $\mathrm{ABA}$ with the $\beta \mathrm{CD}$ in solid state, at molar ratio of 1:1, and used for comparison purposes in solid state characterizations.

\section{Preparation of HNPs}

HNPs were prepared by dissolution of appropriate amounts of $\mathrm{ABA}$ and $\mathrm{ABA} / \beta \mathrm{CD}$ in dimethyl sulfoxide 
(DMSO, as co-solvent) to promote the initial solubilization of compounds. Further, these solutions were verted in water and spontaneous precipitation of nanostructured materials were observed. These compounds were used in bioassays against $A$. aegypti.

\section{Solid-state characterization: FTIR spectroscopy and thermal analysis}

The infrared spectra of $\mathrm{ABA}, \mathrm{ABA} / \beta \mathrm{CD}$, and $\mathrm{MM}$ were obtained using a PerkinElmer Fourier transform infrared spectrometer (Spectrum Two ${ }^{\mathrm{TM}}$ model, PerkinElmer Inc., Waltham, USA). The samples were mixed with $\mathrm{KBr}$ matrix and pressed to form a pellet. The spectra were obtained in the range from 4000 to $400 \mathrm{~cm}^{-1}$ (resolution of $2 \mathrm{~cm}^{-1}$ ), as the mean of 16 consecutive scans. The PerkinElmer Spectrum ES software, version: 10.03.08.0133, was used for the spectra acquisition and processing.

Differential thermal analysis (DTA) and thermogravimetric analysis (TGA) for $\mathrm{ABA}, \beta \mathrm{CD}, \mathrm{ABA} / \beta \mathrm{CD}$, and MM were performed using a simultaneous TGA/DTA thermoanalytical equipment (HITACHI-STA 7200 RV model, Hitachi High-Tech Corporation, Tokyo, Japan). The analytical conditions were: air atmosphere at $300 \mathrm{~mL} \mathrm{~min}^{-1}$, with a temperature ramp from 35 to $700{ }^{\circ} \mathrm{C}$, a heating rate of $15^{\circ} \mathrm{C} \mathrm{min}-1$, and mass of ca. $3.0 \mathrm{mg}$ of the samples in a platinum crucible. The empty platinum crucible was used as reference. The final data were exported to Microcal Origin $^{\circledR} 9.0^{21}$ for editing.

\section{NMR spectroscopy}

The samples (ABA, $\beta C D$ or ABA/ $\beta C D$ ) were dissolved in DMSO- $d_{6}$ (Cambridge Isotope Laboratories, Tewksbury, MA, USA) at final concentrations of $0.1 \mathrm{mmol} \mathrm{L}^{-1}$. Their ${ }^{1} \mathrm{H}$ NMR spectra were recorded at $27^{\circ} \mathrm{C}$ on a Bruker DRX 400-AVANCE spectrometer (Bruker BioSpin, Rheinstetten, Germany) operating at $400 \mathrm{MHz}$, equipped with a $5 \mathrm{~mm}$ inverse probe with a z-gradient coil. The WATERGATE technique was applied for suppression of the residual water signal. The nuclear Overhauser enhancement spectroscopy $\left({ }^{1} \mathrm{H}-{ }^{1} \mathrm{H}\right.$ NOESY) experiment (mixing time $500 \mathrm{~ms}$ ) were acquired for $\mathrm{ABA} / \beta C D$ sample, using standard experiments from the spectrometer library.

\section{Phase solubility diagram}

The solubility diagram of the abamectin in water, in the presence of $\beta C D$ was obtained using the established procedure by Higuchi and Connors. ${ }^{20}$ In $10 \mathrm{~mL}$ test tubes (11 tubes) $1 \mathrm{mg}$ of the abamectin was added. Then, a predefined volume of the $\beta C D$ stock solution $\left(15 \mathrm{mmol} \mathrm{L}^{-1}\right)$ was added in Milli- $\mathrm{Q}^{\circledR}$ water. The final volume in the tube was adjusted to $3 \mathrm{~mL}$ with Milli-Q ${ }^{\circledR}$ water. The concentration range of $\beta C D$ was between 0 to $15 \mathrm{mmol} \mathrm{L}^{-1}$. These suspensions were put into a thermostatic bath with stirring at $30.0 \pm 0.1{ }^{\circ} \mathrm{C}$ for $48 \mathrm{~h}$. After this period, the supernatant was filtered using a Millipore ${ }^{\circledR}$ filter of $0.22 \mu \mathrm{m}$ and transferred to quartz cuvettes with $1 \mathrm{~cm}$ of optical path. The amount of the guest molecule in the supernatant was determined using PerkinElmer UV-Vis spectrophotometer (Lambda-25 model, PerkinElmer Inc., Waltham, USA), containing automatic exchange for eight samples, coupled to a Peltier thermostatic bath $\left(20-60{ }^{\circ} \mathrm{C}\right)$ and managed by the UV WinLab software. The blank used in this test was Milli-Q ${ }^{\circledR}$ water. After obtaining the spectra, the data were transferred and edited in the program Microcal Origin $^{\circledR} 9.0 .^{21}$

\section{ITC experiment}

The thermodynamic parameters involved in the inclusion compound formation between guest molecule and $\beta C D$ in solution were determined using isothermal calorimetric titration (at $25^{\circ} \mathrm{C}$ ). The titrant consisted of a DMSO: $\mathrm{H}_{2} \mathrm{O}(9: 1 \mathrm{v} / \mathrm{v})$ solution of ABA at $30.0 \mathrm{mmol} \mathrm{L}^{-1}$, while the titrand consisted of a DMSO: $\mathrm{H}_{2} \mathrm{O}(9: 1 \mathrm{v} / \mathrm{v})$

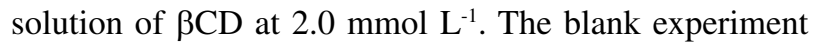
consisted of ABA solution in the solvent (DMSO: $\mathrm{H}_{2} \mathrm{O}$, 9:1 v/v solution) titration. The DMSO: $\mathrm{H}_{2} \mathrm{O}$ solvent was used due to the following reasons: $(i)$ the very low solubility of ABA; (ii) the fact that the hydrophobic nanoprecipitates are obtained by previous solubilization of free and complexed ABA in DMSO, before their mixture in water; (iii) the knowledge of $\mathrm{ABA} / \beta \mathrm{CD}$ equilibrium constant in DMSO is important to evaluate the trend of complex dissociate in this solvent. In otherwise, the pure DMSO was not used as solvent because it is very hygroscopic and the absorption of water during the experiment can cause errors during the measure of heat.

The experiments were performed using a microcalorimeter VP-ITC (Microcal Company, Northampton, MA, USA). The following experimental parameters were used: $300 \mathrm{rpm}$ rotation; 51 automatic $5.0 \mu \mathrm{L}$ injections of titrant in $1.5 \mathrm{~mL}$ of the titrand; $2 \mathrm{~s}$ injection time; and 5 min equilibration time. The first injection of $1.0 \mu \mathrm{L}$ was discarded in order to eliminate the diffusion material effects from the syringe to the cell and vice versa. After the experiments, the titration curves were subtracted from the respective blanks in order to mathematically eliminate the interaction effects of the guest molecules with the solvent. The data were treated using Microcal Origin ${ }^{\circledR} 7.0$ program for ITC. ${ }^{22}$ 


\section{DLS and ZP of HNPs}

DLS experiments were performed in a Malvern Zetasizer Nano ZS particle analyzer (Malvern Instruments Ltd., Malvern, Worcestershire, UK), using polyethylene square cells to measure the average hydrodynamic diameter $\left(D_{h}\right)$ of $\mathrm{ABA}, \mathrm{ABA} / \beta \mathrm{CD}$ hydrophobic nanoprecipitates spontaneously formed by the mixture of their DMSO solutions in water. Initially, it was prepared solutions containing $1.0 \mathrm{mg}$ of $\mathrm{ABA}$ or equimolar amounts of $\mathrm{ABA} / \beta \mathrm{CD}$ in $0.5 \mathrm{~mL}$ of DMSO. Then, 25 injections of $20.0 \mu \mathrm{L}$ of these solutions were titrated in $2.0 \mathrm{~mL}$ of Milli-Q ${ }^{\circledast}$ water, with subsequent measurements of $D_{h}$ for the formed colloidal suspensions. These suspensions were submitted to a monochromatic light (4 $\mathrm{mW} \mathrm{He-Ne} \mathrm{laser,}$ wavelength $633 \mathrm{~nm}$ ) and the scattered light intensity was measured at an angle of $90^{\circ}$. The $\mathrm{D}_{\mathrm{h}}$ were determined by the average of five independent measurements, each of them obtained as the mean of 10 counts, with intervals of $2 \mathrm{~s}$ each.

ZPs were also determined in the Malvern Zetasizer Nano ZS 90 by means of the laser Doppler microelectrophoresis technique ${ }^{23}$ at a scattering angle of $173^{\circ}$ using a glass cuvette into which the measuring cell (dip cell) was immersed. ZP values were calculated as the average of 10 independent measurements, each of them obtained as the mean of 30 counts. The same procedure used in the hydrodynamic diameter experiments was used here.

\section{Bioassays involving Aedes aegypti larvae}

The Aedes aegypti (PPCampos strains) eggs were donated by the Departamento de Biologia Geral from Universidade Federal de Viçosa, MG, Brazil. They were placed in plastic basins containing $2 \mathrm{~L}$ of dechlorinated water, with a temperature of $26 \pm 2{ }^{\circ} \mathrm{C}$, relative humidity $(\mathrm{RH})>70 \%$ and photoperiod of 12L:12D.

The larvicidal activity of the obtained HNPs on $1^{\text {st }}$ instar larvae was evaluated using the method recommended by Pridgeon et al. ${ }^{8}$ with small modifications. After $24 \mathrm{~h}$ (after the eggs hatch), five $1^{\text {st }}$ instar larvae were added to an Eppendorf ${ }^{\circledR}$ tube along with $940 \mu \mathrm{L}$ of dechlorinated water and $10 \mu \mathrm{L}$ of a suspension of food. Then $50 \mu \mathrm{L}$ of the compound was added in such a way that the final solution $(\mathrm{V}=1,000 \mu \mathrm{L})$ had the desired concentration of the tested compound and $1 \%(\mathrm{v} / \mathrm{v})$ DMSO. Seven concentrations were evaluated in the range from 0.0001 to $100 \mu \mathrm{mol} \mathrm{L}^{-1}$ in $1 \%$ DMSO aqueous solution. After $24 \mathrm{~h}$ of exposure to the compound, the number of dead larvae was recorded. The larvae were considered dead when they did not respond to a stimulus or did not rise to the surface of the liquid.
For each concentration, three independent experiments were performed in triplicate. Dechlorinated water and $1 \%$ DMSO aqueous solutions were used as negative controls. The mortality percentage curves versus the compound concentration logarithm were constructed and the data fitted using dose-response model, $\log$ (inhibitor) $v s$. response (there parameters), provided by GraphPad Prism 5.024 software, being calculated the $\mathrm{LC}_{50}$. As a negative control, water, $\beta C D$ and $1 \%$ DMSO solution were used.

The larvicidal activity of the obtained HNPs on $4^{\text {th }}$ instar larvae was evaluated using the method recommended by the World Health Organization (WHO) with small modifications..$^{25}$ Briefly, twenty $4^{\text {th }}$ instar larvae were added to a beaker $(250 \mathrm{~mL})$ together with $50 \mathrm{~mL}$ of dechlorinated water and food. Thereon, $50 \mathrm{~mL}$ of each sample stock solution was added to the beaker so that suspension reached the desired concentration of the compound and $1 \%$ DMSO in volume. The nominal concentrations used in experiments for each HNP were $10^{2}, 10^{1}, 10^{0}, 10^{-1}, 10^{-2}$ and $10^{-3} \mu \mathrm{mol} \mathrm{L}^{-1}$. Mortality of the larvae was determined after 24 and $48 \mathrm{~h}$ of incubation at $26 \pm 2{ }^{\circ} \mathrm{C}$ and $\mathrm{RH}>70 \%$. The larvae were considered dead when they did not demonstrate any response to the external stimulus. Three replicates were performed in three independent experiments. Dechlorinated water and 1\% DMSO aqueous solutions were evaluated as negative controls. In this biossay, when the mortality percentage in the controls was between 5 and $20 \%$, the mortality percentages of the treated groups in this independent experiment were corrected according to Abbott's formula. The mortality percentage curves versus the compound concentration logarithm were constructed and fitted using the GraphPad Prism 5.0 software ${ }^{24}$ and $\mathrm{LC}_{50}$ values, at 24 and $48 \mathrm{~h}$, were calculated.

\section{Results and Discussion}

Solid-state characterization: FTIR spectroscopy and thermal analysis

Figure 1 shows the infrared spectra of $A B A, \beta C D, M M$ and the inclusion compound (ABA/ $\beta C D$ ) in the 4000 to $400 \mathrm{~cm}^{-1}$ range. The main absorptions in $\beta C D$ spectrum were associated to stretching of $\mathrm{O}-\mathrm{H}$ bond centered at $3380 \mathrm{~cm}^{-1}$; stretching of $\mathrm{C}-\mathrm{H}$ centered at $2927 \mathrm{~cm}^{-1}$; bending of $\mathrm{O}-\mathrm{H}$ bonds for free water at $1639 \mathrm{~cm}^{-1}$; bending of $\mathrm{CH}_{2}$ bonds at $1416 \mathrm{~cm}^{-1}$; and the skeletal vibration ${ }^{26}$ involving the $\alpha-1,4$ linkage at $942 \mathrm{~cm}^{-1}$.

For ABA, the main observed bands were associated to stretching of $\mathrm{O}-\mathrm{H}$ bond centered at $3473 \mathrm{~cm}^{-1}$, stretching of $\mathrm{C}-\mathrm{H}$ bond at $2967 \mathrm{~cm}^{-1}$, stretching of $\mathrm{C}=\mathrm{O}$ bonds of the macrolide ring at 1713 and $1736 \mathrm{~cm}^{-1}$; stretching of 
$\mathrm{C}-\mathrm{O}-\mathrm{C}$ bond at $1300 \mathrm{~cm}^{-1}$ and stretching of $\mathrm{C}=\mathrm{C}$ bonds of conjugated alkenes at $1669 \mathrm{~cm}^{-1}$.

In MM spectrum, no changes in the positions of the main bands were observed in relation to free $\mathrm{ABA}$ or to free $\beta C D$. In the spectrum of $A B A / \beta C D$, it was observed a significant alteration in region from 1200 to $900 \mathrm{~cm}^{-1}$, being apparent that vibrations modes associated to $\beta C D$ are highlighted in relation to vibrations of free ABA. Moveover, this behavior is different from MM. This and other alterations in $\mathrm{ABA} / \beta \mathrm{CD}$ spectrum suggest generic interactions of $\mathrm{ABA}$ with $\beta C D$ in solid state.

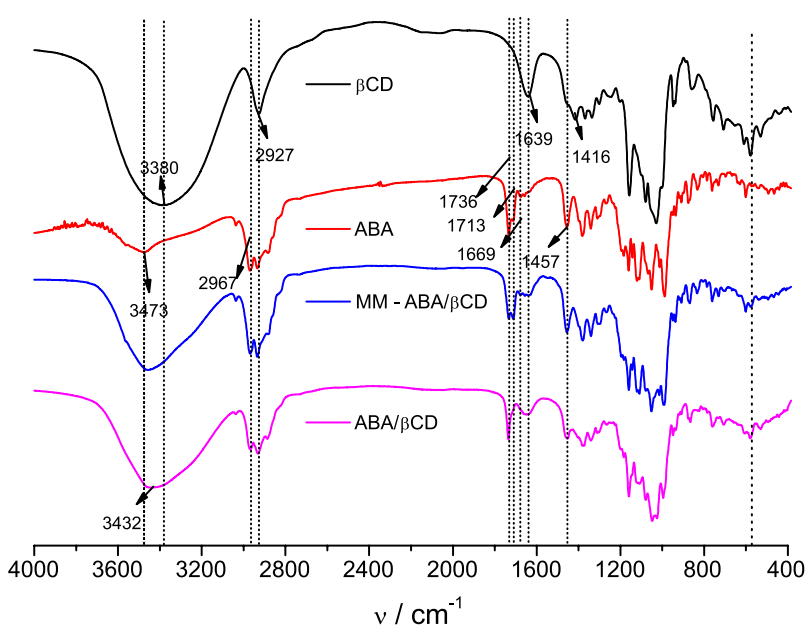

Figure 1. FTIR spectra of $A B A, \beta C D, M M$ and $A B A / \beta C D$ in $K B r$ pellets.

The data obtained from the thermal analysis allowed to verify changes in the thermal profiles of inclusion compound and showed that the dehydration/decomposition events occurred at intermediate temperatures between the identified for the free molecule, as well as with different thermal profiles in relation to the MM, signaling the formation of the compounds of inclusion in the solid state.
Figure 2a shows the TGA and DTA (Figure $2 b$ ) curves of $\beta C D, A B A, M M$ and $A B A / \beta C D$. The $\beta C D$ showed a loss of mass of $\Delta \mathrm{m} / \mathrm{m}_{0}$ ca. $14.9 \%$ in the range $30-106{ }^{\circ} \mathrm{C}$, corresponding to the releasing of ca. 11 water molecules by cyclodextrin $\left(\beta \mathrm{CD} \cdot 11 \mathrm{H}_{2} \mathrm{O}\right)$, being a reasonable value for hydration, according with literature. ${ }^{27,28}$ In the DTA curve, it was observed an endothermic peak started at ca. $70^{\circ} \mathrm{C}$, with a maximum at $95{ }^{\circ} \mathrm{C}$, confirming the dehydration. After this event, it remained stable until ca. $280^{\circ} \mathrm{C}$, when its decomposition begins. ${ }^{16}$ The TGA curve of ABA shows that the compound has its decomposition initialized at $175^{\circ} \mathrm{C}$, which is followed by a sequence of thermal events of decomposition. In the DTA curve, discrete endothermic peaks of decomposition were observed with maximum in $288.7^{\circ} \mathrm{C}$.

For MM, TGA curve presents three events, the first being attributed to $\beta \mathrm{CD}$ dehydration in the range very close to that observed for free molecule $\left(30.0\right.$ to $\left.102.9^{\circ} \mathrm{C}\right)$. The other events (ranging from 213.5 to $344.8^{\circ} \mathrm{C}$ and from 344.8 to $649.0^{\circ} \mathrm{C}$ ) correspond to the decomposition of mixture presenting a different thermal profile in relation to free molecules. Through the DTA, it is possible to observe that all of these events are endothermic.

In the curve of TGA of $A B A / \beta C D$, there are three thermal events similar to those observed for MM. The first corresponds to the loss of mass due to $\beta \mathrm{CD}$ dehydration, occurring in a smaller range $\left(30\right.$ at $\left.89^{\circ} \mathrm{C}\right)$ and with lower loss of mass when compared to $\mathrm{MM}$ and free $\beta \mathrm{CD}$, due to the previous releasing of water molecules upon inclusion. The decomposition of the complex begun at $185^{\circ} \mathrm{C}$, suggesting a greater thermal stability of complex if compared with precursors and MM, due to interactions. Moreover, the different profile of mass loss observed for inclusion compound if compared with MM is an indicative of interactions, which are resultant from the contact of reagents in liquid phase.
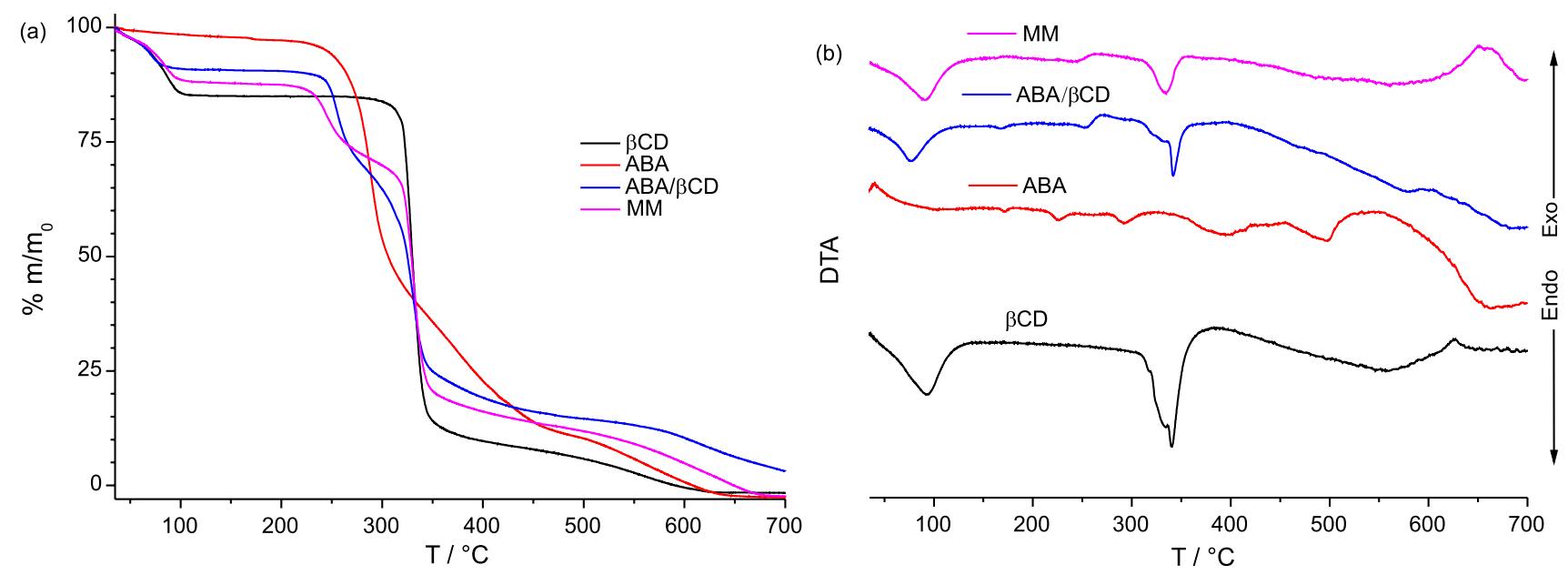

Figure 2. (a) TGA and (b) DTA curves for $A B A, \beta C D, A B A / \beta C D$ and $M M$ in air atmosphere. 
Characterization in solution/suspension NMR spectroscopy: structural characterization of inclusion complex in solution

NMR spectroscopy was used to characterize inclusion compound in solution providing structural information such as molecular orientation of the substance host within the cyclodextrin cavity. The formation of complexes with cyclodextrins usually generates changes in the chemical environment around the hydrogen nuclei involved in the interactions and undergoes changes in signals as they are in a chemical environment distinct from the one where they were originally solvated. ${ }^{29,30}$

In Figure 3 are shown the ${ }^{1} \mathrm{H}$ NMR spectra of $\mathrm{ABA}, \beta C D$ and $\mathrm{ABA} / \beta \mathrm{CD}$ in DMSO- $d_{6}$ solvent. The ${ }^{1} \mathrm{H}$ NMR spectrum of $\beta C D$ was similar to others found in literature for this solvent, being observed signs referring to the hydrogens $1-6$ of the glycopyranoside monomer. ${ }^{16}$

The ${ }^{1} \mathrm{H}$ NMR spectrum of ABA was similar to the described in the literature. ${ }^{31}$ Due to the molecule structural complexity, the signals of their hydrogens were assigned based on the joint analysis of literature data and of the single and two-dimensional spectra.

$\mathrm{ABA} / \beta C D$ complex showed changes in chemical shifts of hydrogens $\mathrm{H}-1, \mathrm{OH}-2, \mathrm{OH}-3$ and $\mathrm{OH}-6 \mathrm{a}$ of $\beta \mathrm{CD}$ and low changes in hydrogens $\mathrm{H}-10, \mathrm{H}-11, \mathrm{H}-19, \mathrm{H}-7 \mathrm{a}, \mathrm{H}-3^{\prime}, \mathrm{OH}-4 \mathrm{a}$, H-6“, H-12a, H-24a, H-26a-H-26b of ABA, which are shown in Table S1 available in Supplementary Information (SI) section. The chemical shifts changes in the external $\beta C D$ hydrogens can be justified by the interaction between $\beta C D$ hydroxyls and these glycosidic subunits of the ABA molecule, in view of the rotational freedom of these groups. The large number of signal shifts involving hydrogens from the ABA benzofuran ring suggests the participation of this group in inclusion complex. The Tables S1 and S2, available in SI section, show the chemical shift changes.

Due to the low changes in chemical shifts observed for $\mathrm{ABA}$ in the ${ }^{1} \mathrm{H}$ NMR spectrum, and in order to improve the understanding about the local intermolecular interactions in ABA/BCD system, 2D NOESY experiment was performed, which showed cross-peak correlations, indicating short distance interactions (less than $5 \AA$ ) between ABA hydrogens and those hydrogens from the $\beta C D$. Figure 4 shows a selected region of the ${ }^{1} \mathrm{H}-{ }^{1} \mathrm{H}$ NOESY contour map, where correlations between $\mathrm{H} 3, \mathrm{H} 1$ ' and $\mathrm{H} 1$ " hydrogens of ABA with $\beta C D$ hydrogens present in the inner of cavity (H3 and $\mathrm{H} 5$ ) and outside (H2 and $\mathrm{H} 4)$ are observed. They were marked with red dot squares, in order to differentiate from intramolecular NOE among hydrogens of ABA, marked with black line square. This data suggests the occurrence of more than one mode of inclusion, which should be in chemical equilibrium. Moreover, the occurrence of NOE with outside hydrogens of $\beta C D$ suggests a complex topology where ABA molecule could bend around the cyclodextrin.

\section{Phase solubility diagram}

Phase solubility experiments allow to demonstrate the cyclodextrin effect on the solubility of a guest molecule and evaluates the interactions between the species. ${ }^{20}$ The
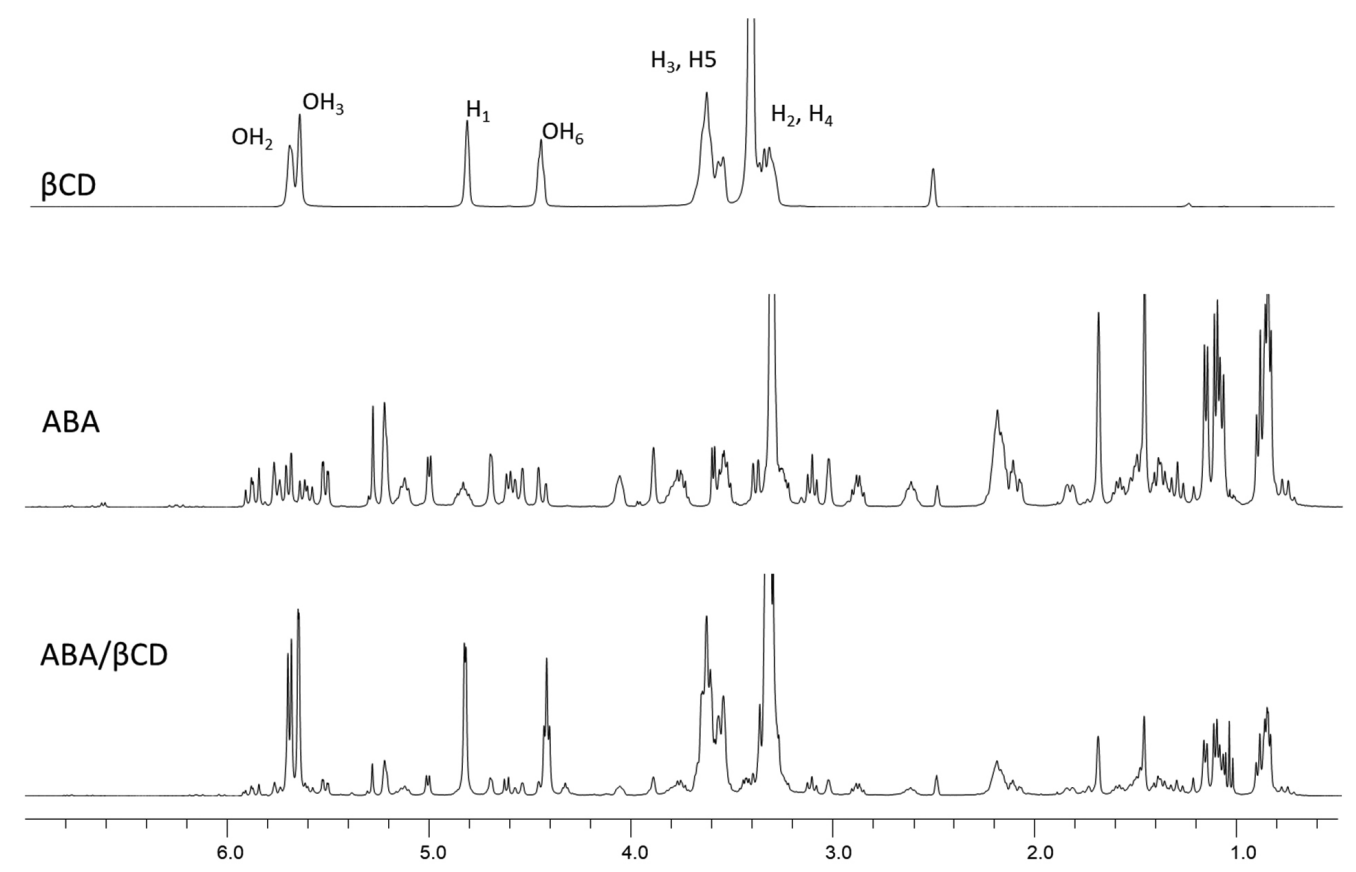

Figure 3. ${ }^{1} \mathrm{H}$ NMR spectra (400 MHz, DMSO- $d_{6}$ ) for $\beta \mathrm{CD}$, ABA and ABA/ $\beta C D(1: 1)$ inclusion compound. Experiment performed at $300 \mathrm{~K}$. 


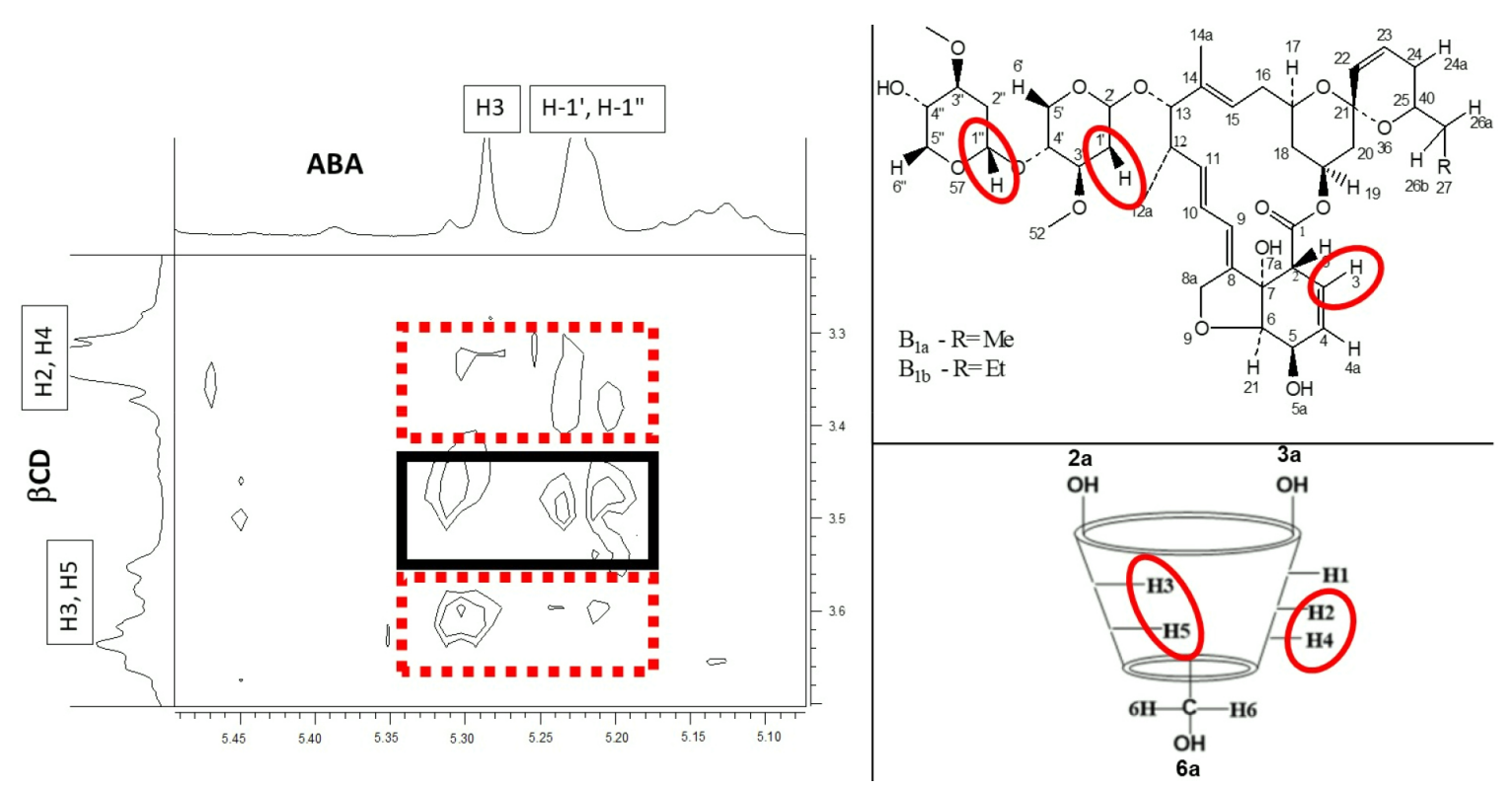

Figure 4. Selected regions in the $2 \mathrm{D}$ NOESY contour map ( $400 \mathrm{MHz}$, DMSO- $d_{6}$ ) for ABA/ $\beta C D$ system $(1: 1)$, at $0.1 \mathrm{mmol} \mathrm{L}^{-1}$. Experiment performed at $300 \mathrm{~K}$.

phase solubility diagrams obtained in the study with $\mathrm{ABA}$ and $\beta C D$ are depicted in Figure 5. Analyzing the phase solubility profiles it is possible to observe the increase of ABA solubility in the system due to molecular interaction with $\beta C D$, in spite of a small reduction of ABA concentration until $[\beta C D]=1 \mu \mathrm{mol} \mathrm{L}^{-1}$. This means that above $1 \mu \mathrm{mol} \mathrm{L} \mathrm{L}^{-1}$, ABA forms a soluble complex with $\beta C D$ in water, showing a typical AL-type solubility diagrams as described by Higuchi and Connors. ${ }^{20}$ However, the solubility of the compound was very low, even in the presence of $\beta C D$, which justify the strategy to prepare the inclusion compounds as hydrophobic nanoprecipitates.

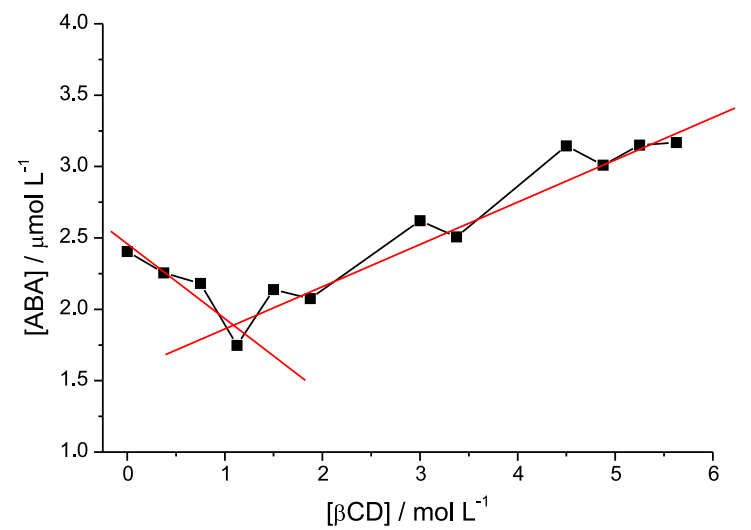

Figure 5. Phase solubility diagram for ABA in increasing concentration of $\beta C D$, at $298 \mathrm{~K}$.

ITC

Figure 6 shows the ABA titration curve in $\beta C D$ in DMSO/ $\mathrm{H}_{2} \mathrm{O}(9: 1 \mathrm{v} / \mathrm{v})$ mixture, where can be observed a strong endothermic signal.
As the curve showed a classical sigmoidal profile, it was possible to find the stoichiometry $\left(\mathrm{N}_{\mathrm{ABA} / \mathrm{BCD}}\right)$ of the complex in the inflexion point of the curve, which was 1:1. The data fitted by the software was $\mathrm{N}_{\mathrm{ABA} / \beta C D}=1.130 \pm 0.007$. This data was used to justify the further preparation of inclusion compounds with this molar ratio to be used in biological experiments.

A sigmoidal profile of the curve, characteristic of compounds with high affinity constants (values close or greater than 20000), suggests a strong interaction between species, and it is consistent with other studies that also obtained high equilibrium constants for their inclusion compounds. ${ }^{32-34}$ With respect to enthalpic contribution, it is observed that the process is endothermic $\left(\Delta \mathrm{H}^{\circ}=1.32 \pm 0.01 \mathrm{~kJ} \mathrm{~mol}^{-1}\right)$, which was ascribed to the desolvation of precursors upon complexation. The process was entropy driven, with entropic contribution of $\mathrm{T} \Delta \mathrm{S}^{\circ}=27.2 \mathrm{~kJ} \mathrm{~mol}^{-1}$, which matches with the hypothesis of desolvation upon complexation. An endothermic process indicates break of intermolecular interactions with subsequent formation of less stable interactions than those existing before complexation. The positive variation in entropy indicates that hydrophobic molecules tend to have molecular interactions known as the "hydrophobic effect" in the inclusion process. This effect is generally endothermic, due to the breakdown of solute-solvent interactions during complexation. ${ }^{16,34}$

\section{Characterization of HNPs by DLS and ZP}

Due to the low solubility of ABA, even in the presence of $\beta C D$, it was proposed to work with the aqueous 


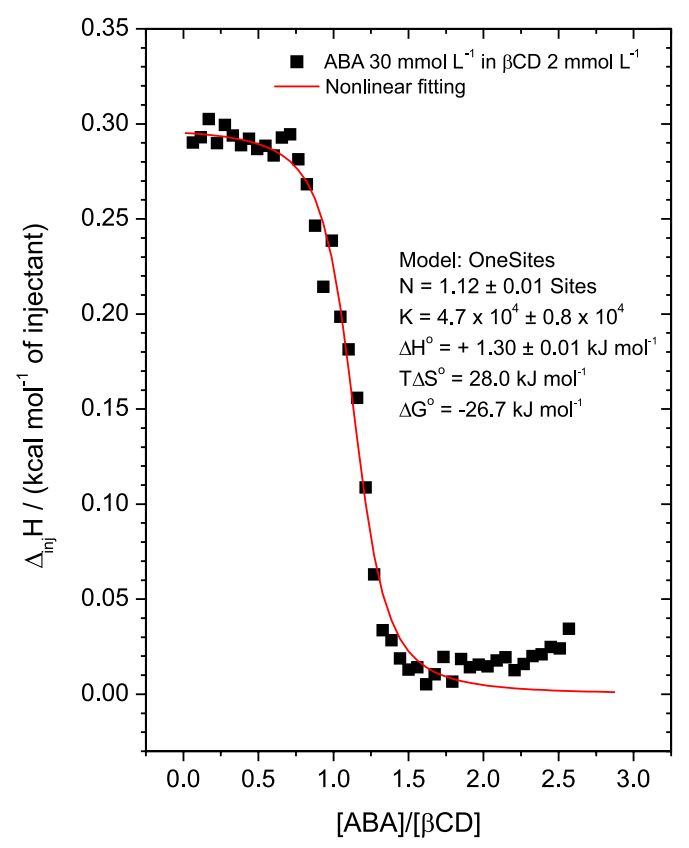

Figure 6. ITC for ABA $30 \mathrm{mmol} \mathrm{L}^{-1}$ in DMSO: $\mathrm{H}_{2} \mathrm{O}$ (90:10) in $\beta C D$ solution $2 \mathrm{mmol} \mathrm{L}^{-1}$ in DMSO (90:10) at $25^{\circ} \mathrm{C}$.

suspension formed by HNPs. The analysis of the $D_{h}$ and ZP properties allowed us to evaluate the colloidal behavior and stability of the systems dispersed in liquid suspensions.

Precipitates form when a particular compound is initially dissolved in a solvent less polar than water but soluble in water, such as DMSO. Then, this mixture is added in water with stirring, immediately forming the nanoprecipitates. Thus, the effect of $\beta C D$ on the formation of these hydrophobic nanoprecipitates was assessed by $D_{h}$ and ZP measurement in DLS experiment. The zeta potential (ZP) is related to the surface charge of the particle and it is closely linked to the stability of the dispersion. When the $\mathrm{ZP}$ is low, there are more unstable dispersions, since high ZP values may indicate greater stability, considering that the charged particles repel each other and this force exceeds the van der Waals forces, which are always of an attractive nature and promote aggregation.

Figure 7 shows the DLS titration of ABA and $\mathrm{ABA} / \beta C D$ DMSO solutions in ultrapure (Milli- $\mathrm{Q}^{\circledR}$ ) water. In titrations involving $\mathrm{ABA}$ and $\mathrm{ABA} / \beta \mathrm{CD}$ it is observed that for concentrations below $250 \mu \mathrm{mol} \mathrm{L} \mathrm{L}^{-1}$ there is no significant difference between the $D_{h}$ values. From this concentration, it appears that the inclusion compound has lower $D_{h}$ values which suggests greater colloidal stability. As result of the size reduction, a larger surface area of the particle is exposed allowing a new pattern of interactions with the medium.

Regarding the ZP data in Figure 8, it is observed that both the free compound and the inclusion compound presented $\mathrm{ZP}$ values in the range between -30 to $+30 \mathrm{mV}$.
This demonstrates that they present similar surface charge behavior, being in the region of instability with the possibility of formation of aggregates and precipitates. Thus, the zeta potential values allow us to infer that $\mathrm{ABA} / \beta \mathrm{CD}$ is unstable and can flocculate. Given these data and the knowledge that feeding in larval stages is intense, fast and indiscriminate through particles present in the water, the fact that inclusion compound is subject to flocculation, even in the presence of $\beta C D$, could be a way to attract them. Thus, it is suggested that nanoprecipitates of inclusion compounds could be used as "bait" designed to attract the desired target or be ingested by it and increase the effectiveness in controlling larvae of the Aedes aegypti mosquito.

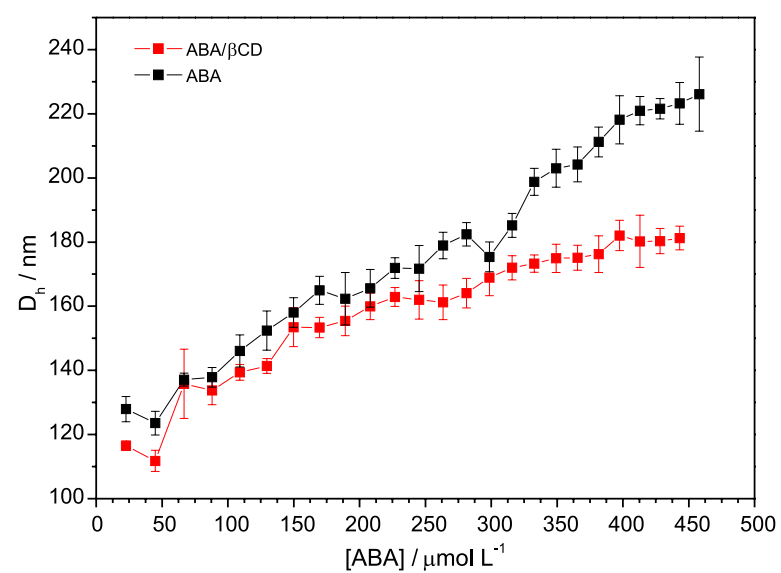

Figure 7. DLS titration of $\mathrm{ABA}$ and $\mathrm{ABA} / \beta \mathrm{CD}$ DMSO solutions in pure water $\left(25^{\circ} \mathrm{C}\right)$.

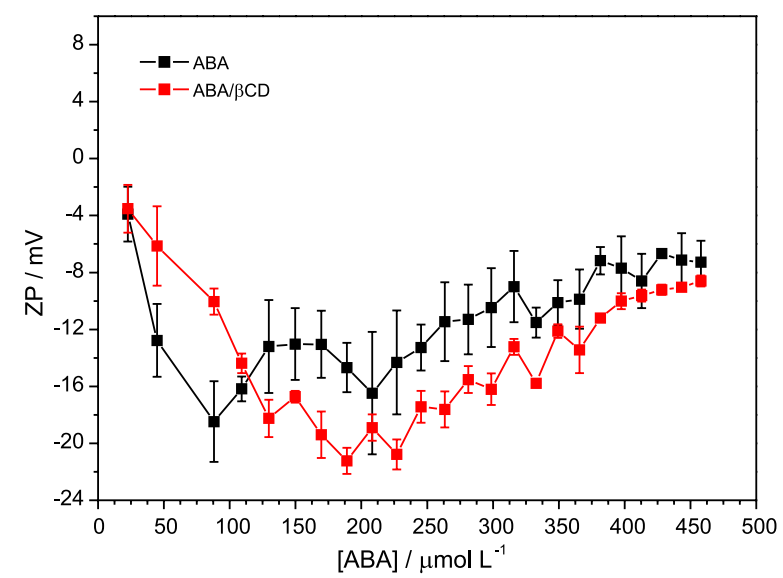

Figure 8. $\mathrm{ZP}$ titrations for $\mathrm{ABA}$ and $\mathrm{ABA} / \beta C D$ DMSO solutions in pure water $\left(25^{\circ} \mathrm{C}\right)$.

\section{Bioassays involving Aedes aegypti larvae}

The larvicidal activity of $\mathrm{ABA}$ and $\mathrm{ABA} / \beta \mathrm{CD}$ HNPs were carried out using two methodologies: one evaluated at the $1^{\text {st }}$ instar larvae and other at $4^{\text {th }}$ instar larvae. The test at the $1^{\text {st }}$ instar larvae, developed by Pridgeon et al. ${ }^{8}$ consists 
Table 1. Larvicide activity $\left(\mathrm{LC}_{50}\right)$ for $\mathrm{ABA}$ and $\mathrm{ABA} / \beta C D$ against $1^{\text {st }}$ and $4^{\text {th }}$ instars of Aedes aegypti larvae

\begin{tabular}{|c|c|c|c|c|c|c|}
\hline \multirow{3}{*}{ Compound } & \multicolumn{6}{|c|}{$\mathrm{LC}_{50}$ (confidence interval) } \\
\hline & \multicolumn{2}{|c|}{$1^{\text {st }}$ instar $(24 \mathrm{~h})$} & \multicolumn{2}{|c|}{$4^{\text {th }}$ instar $(24 \mathrm{~h})$} & \multicolumn{2}{|c|}{$4^{\text {th }}$ instar $(48 \mathrm{~h})$} \\
\hline & $\left(\mu \mathrm{mol} \mathrm{L}{ }^{-1}\right)$ & ppm & $(\mu \mathrm{mol} \mathrm{L}-1)$ & ppm & $(\mu \mathrm{mol} \mathrm{L}-1)$ & ppm \\
\hline ABA & 1.198 (1.143 to 1.256$)$ & $1.046(0.998-1.096)$ & $0.629(0.475-0.832)$ & $0.549(0.414-0.726)$ & $0.148(0.101-0.216)$ & $0.129(0.088-1.889)$ \\
\hline $\mathrm{ABA} / \beta \mathrm{CD}$ & $0.046(0.036-0.058)$ & $0.040(0.031-0.051)$ & $0.331(0.251-0.435)$ & $0.289(0.219-0.379)$ & $0.099(0.062-0.1571)$ & $0.086(0.054-0.137)$ \\
\hline
\end{tabular}

ABA: abamectin; $\beta C D$ : $\beta$-cyclodextrin.

of a screening test that provides quickly information about the toxic potential of compounds under analysis. The test at the $4^{\text {th }}$ instar larvae is recommended by the $\mathrm{WHO}^{25}$ to verify the larvicidal activity of fast-acting compounds for insects, both in the laboratory and in field, since from this test one can observe the acute action of the compounds. ${ }^{25}$

Table 1 shows the $\mathrm{LC}_{50}$ values obtained for $\mathrm{ABA}$ and $\mathrm{ABA} / \beta C D$ in both experiments. The free $\beta C D$ was inactive at tested concentration, showing mortality percentages between $6-9 \%$ at $100 \mu \mathrm{mol} \mathrm{L}^{-1}$. In this same bioassay, the mortality percentages of dechlorinated water and $1 \%$ for DMSO aqueous solution (negative controls) were 2-7\% and $5-10 \%$, respectively.

All the obtained results were equal to or less than $1 \mathrm{ppm}$, which demonstrates the high activity of these compounds against $A$. aegypti larvae. ${ }^{30}$ This must be associated to the mechanism of action of avermectin in invertebrates, that prevents the transmission of electrical impulses in the muscles and nerves by amplifying the glutamate effects on the invertebrates-specific gated chloride channel, causing hyperpolarization and culminating in paralysis of the invertebrate neuromuscular systems. ${ }^{35}$ Furthermore, a decreasing in $\mathrm{LC}_{50}$ values was observed in the two bioassays for the $\mathrm{ABA} / \beta \mathrm{CD}$, being more significant in test in $1^{\text {st }}$ instar larvae. The higher activity for the $A B A / \beta C D$ was attributed to its higher solubility and the lower size of HNPs, so that these both factors can improve the absorption of the $\mathrm{ABA}$ by the larvae, and consequently, the action of the compound.

\section{Conclusions}

In this work, $\mathrm{ABA} / \beta \mathrm{CD}$ inclusion compound and its HNPs were properly prepared and characterized. In summary, the infrared spectra and thermal analysis indicated the occurrence of interaction between $A B A$ and $\beta C D$ in solid state. Isothermal titration calorimetry confirmed this interaction in solution, with stoichiometry of 1:1. Moreover, the NMR techniques were important to understand the possible modes of interactions in solution. The DLS experiment allowed us to observe the size reduction for the hydrophobic nanoprecipitate formed in the presence of $\beta C D$. Analysis of the zeta potential data revealed that the compound is unstable and may flocculate. However, considering the application of these compounds, this characteristic is beneficial, since formulations of this type can favor the ingestion of the compounds by the larvae. The results for the larvicidal activity demonstrated that $\mathrm{ABA} / \beta \mathrm{CD}$ was more potent than its precursor, specially against $1^{\text {st }}$ instar larvae stage. Finally, the strategy of revisiting ABA already used to control other arthropods combined with molecular encapsulation resulted in an improvement of its potency. Regarding avermectins have a different mechanism of action compared with compounds used today in the chemical control of mosquito larvae, this result can contribute to increasing the arsenal of insecticides used to control larvae in the A. aegypti.

\section{Supplementary Information}

Supplementary information (Tables S1 and S2) is available free of charge at http://jbcs.sbq.org.br as PDF file.

\section{Acknowledgments}

The authors are grateful to the Foundation for Research Support of Minas Gerais State (FAPEMIG: APQ-0353616, APQ-03623-17 and APQ-01293-14), the National Council for Scientific and Technological Development (CNPq 308278/2020-8, 437418/2018-9), the "Research and Studies" Financier (FINEP 0633/13), and LABINT/ DRI - Federal University of Juiz de Fora (UFJF).

\section{Author Contributions}

Vanessa C. E. Bittencourt was responsible for investigation; Ana M. S. Moreira for investigation; Alexandre A. Ferreira for writing original draft, data curation; Erúzia A. E. Ferreira for writing original draft, data curation; Antônio F. F. Gomides for validation; Cibele V. Rodrigues for conceptualization, formal analysis funding acquisition; Gustavo F. Martins for validation; Jeferson G. da Silva for project administration, software; Keyller B. Borges for conceptualization, formal analysis funding 
acquisition; Ângelo M. L. Denadai for conceptualization, project administration, writing-review and editing.

\section{References}

1. Dewick, P. M.; Medicinal Natural Products: A Biosynthetic Approach; John Wiley \& Sons, Ltd: England, 2009.

2. Novelli, A.; Vieira, B. H.; Cordeiro, D.; Cappelini, L. T. D.; Vieira, E. M.; Espindola, E. L. G.; Chemosphere 2012, 86, 36.

3. Tisler, T.; Erzen, N. K.; Ecotoxicology 2006, 15, 495.

4. Mahmood, F.; Walters, L. L.; Guzman, H.; Tesh, R. B.; J. Med. Entomol. 1991, 28, 701.

5. Derua, Y. A.; Malongo, B. B.; Simonsen, P. E.; Parasites Vectors 2016, 9, 131.

6. Pampiglione, S.; Majori, G.; Petrangeli, G.; Romi, R.; Trans. R. Soc. Trop. Med. Hyg. 1985, 79, 797.

7. Deus, K. M.; Saavedra-Rodriguez, K.; Butters, M. P.; Black, W. C.; Foy, B. D.; J. Med. Entomol. 2012, 49, 356.

8. Pridgeon, J. W.; Pereira, R. M.; Becnel, J. J.; Allan, S. A.; Clark, G. G.; Linthicum, K. J.; J. Med. Entomol. 2008, 45, 82.

9. Rosa, C. S.; Albeny, D. S.; Ataíde, L. M. S.; Horta, M. A. P.; Vilela, E. F.; BioAssay 2011, 6, 1.

10. Guy, B.; Barrere, B.; Malinowski, C.; Saville, M.; Teyssou, R.; Lang, J.; Vaccine 2011, 29, 7229.

11. Lima, E. P.; de Oliveira, A. M.; Lima, J. W. D.; Junior, A. N. R.; Cavalcanti, L. P. D.; Pontes, R. J. S.; Rev. Soc. Bras. Med. Trop. 2006, 39, 259.

12. Miranda, T. M.; Oliveira, A. R.; Andrade, L. M. D.; Silva, G. F.; da Silva, J. G.; Ferreira, G. F.; Denadai, A. M. L.; J. Inclusion Phenom. Macrocyclic Chem. 2020, 97, 205.

13. de Paula, W. X.; Denadai, A. M. L.; Braga, A. N. G.; Shastri, V. P.; Pinheiro, S. V. B.; Frezard, F.; Santos, R. A. S.; Sinisterra, R. D.; Drug Dev. Ind. Pharm. 2018, 44, 1498.

14. Teixeira, K. I. R.; Denadai, A. M. L.; Sinisterra, R. D.; Cortes, M. E.; Drug Delivery 2015, 22, 444.

15. Bittencourt, V. C. E.; Moreira, A. M. D.; da Silva, J. G.; Gomides, A. F. D.; Velloso-Rodrigues, C.; Kelmann, R. G.; Mendonca, L. M.; Lula, I. S.; Denadai, A. M. L.; Heliyon 2019, 5, e02013.

16. Moreira, A. M. D.; Bittencourt, V. C. E.; Costa, F. L. S.; de Lima, M. E.; Lopes, M. T. P.; Borges, W. S.; Martins, G. F.; Nascimento, C. S.; da Silva, J. G.; Denadai, A. M. L.; Borges, K. B.; J. Agric. Food Chem. 2018, 66, 7275.

17. Lankas, G. R.; Gordon, L. R. In Ivermectin and Abamectin; Campbell, W. C., ed.; Springer: New York, 1989, p. 89.
18. United States Environmental Protection Agency; Pesticide Fact Sheet; available at https://nepis.epa.gov/Exe/ZyPURL. cgi?Dockey=91024L3O.txt, accessed in June 2021.

19. Pirasath, S.; Nageswaran, B.; Vasana Karunasena, R. P.; Gevakaran, M.; Toxicol. Commun. 2021, 5, 66.

20. Higuchi, T.; Connors, K.; Adv. Anal. Chem. Instrum. 1969, 4 , 117.

21. Origin, v.9.0; Origin Lab Corporation, Microcal, Massachusetts, USA, 2012.

22. Origin for ITC, v.7.0; Origin Lab Corporation, Microcal, Northampton, USA, 2015.

23. Xu, R. L.; Langmuir 1993, 9, 2955.

24. Motulsky, H. J.; Prism, 5; GraphPad Software Inc., San Diego, California, USA, 2007.

25. World Health Organization (WHO); Guidelines for Laboratory and Field Testing of Mosquito Larvicides, available at https:// apps.who.int/iris/handle/10665/69101, accessed in June 2021.

26. Egyed, O.; Vib. Spectrosc. 1990, 1, 225.

27. Correa, J. M. L.; Abrishamkar, A.; da Silva, J. G.; Pereira, J. R.; de Oliveira, F. C.; Denadai, A. M. L.; J. Mol. Struct. 2015, $1100,438$.

28. Giordano, F.; Novak, C.; Moyano, J. R.; Thermochim. Acta 2001, 380, 123.

29. Denadai, A. M. L.; Santoro, M. M.; Texeira, A. V.; Sinisterra, R. D.; Mater. Sci. Eng., C 2010, 30, 417.

30. Lula, I.; de Sousa, F. B.; Denadai, A. M. L.; de Lima, G. F.; Duarte, H. A.; Guia, T. R. D.; Faljoni-Alario, A.; Santoro, M. M.; de Camargo, A. C. M.; dos Santos, R. A. S.; Sinisterra, R. D.; Mater. Sci. Eng., C 2012, 32, 244.

31. Awasthi, A.; Razzak, M.; Al-Kassas, R.; Greenwood, D. R.; Harvey, J.; Garg, S.; Curr. Pharm. Anal. 2012, 8, 415.

32. Li, J. F.; Zhang, J. X.; Wang, Z. G.; Yao, Y. J.; Han, X.; Zhao, Y. L.; Liu, J. P.; Zhang, S. Q.; Food Chem. 2017, 221, 296.

33. Zheng, Y.; Dong, L. N.; Liu, M.; Chen, A. J.; Feng, S. C.; Wang, B. Q.; Sun, D. Z.; J. Agric. Food Chem. 2014, 62, 244.

34. Miranda, T. M.; de Oliveira, A. R.; Pereira, J. R.; da Silva, J. G.; Lula, I. S.; Nascimento, C. S.; Denadai, A. M. L.; J. Mol. Struct. 2019, 1184, 289.

35. Batiha, G. E. S.; Alqahtani, A.; Ilesanmi, O. B.; Saati, A. A.; El-Mleeh, A.; Hetta, H. F.; Beshbishy, A. M.; Pharmaceuticals 2020, 13 .

Submitted: March 15, 2021

Published online: June 29, 2021 